\title{
Rapid climate change: scientific challenges and the new NERC programme
}

\author{
By M. A. SROKOSZ \\ Southampton Oceanography Centre, European Way, \\ Southampton SO14 3ZH, UK (m.srokosz@soc.soton.ac.uk)
}

Published online 22 July 2003

In this paper the scientific challenges of observing, modelling, understanding and predicting rapid changes in climate are discussed, with a specific focus on the role of the Atlantic thermohaline circulation. The palaeo and present-day observational and modelling studies being carried out to meet these challenges, under the aegis of a new NERC Rapid Climate Change thematic programme (RAPID), are outlined. In particular, the paper describes the work being done to monitor changes in the meridional overturning circulation of the North Atlantic. The paper concludes with some speculative comments about potential mechanisms for rapid changes.

Keywords: rapid climate change; thermohaline circulation; palaeo;

modelling; observations; Atlantic

\section{Introduction and background}

A range of model studies show that the presence of the oceanic thermohaline circulation (THC) and its northward Atlantic heat transport produces a substantially warmer climate in western Europe than would otherwise be the case (Manabe \& Stouffer 1988; Schiller et al. 1997; Vellinga \& Wood 2002). The THC consists of deep convection induced by surface cooling at high latitudes, sinking to depth, and upwelling of deep waters at lower latitudes, with horizontal shallow and deep currents feeding these vertical flows. The deep convection and sinking in the North Atlantic (in the Labrador and Greenland Seas) have no counterpart in the North Pacific Ocean, where northward heat transport is consequently much weaker. However, the Atlantic THC has not always been like today's. Palaeoclimate records indicate that abrupt change has occurred in the Northern Hemisphere, especially during and just after the last cold stage (Broecker \& Denton 1989; Dansgaard et al. 1993; Broecker 2000), with THC change as the most plausible mechanism. Similar changes might occur in the future. Model results suggest that the human-induced increase in the atmospheric concentration of $\mathrm{CO}_{2}$ and other greenhouse gases will lead to a significant reduction in the strength of the Atlantic THC (Manabe \& Stouffer 1993; Wood et al. 1999). This in turn will modify the projected rate and possibly the direction (cooling versus warming) of climate change over western Europe substantially. Furthermore, changes could occur rapidly, perhaps over as short a period as 10-20 years.

One contribution of 14 to a Discussion Meeting 'Abrupt climate change: evidence, mechanisms and implications'. 
Such rapid climate change would make adaptation to, and mitigation of, the impacts exceedingly difficult for the affected countries. Therefore, it would be useful to estimate the probability of such changes. However, while most climate models indicate that there will be THC weakening, there is considerable spread between their projections (Cubasch et al. 2001), and at least two models show no change at all (Latif et al. 2000; Gent 2001).

Thus, while there is a possibility that the North Atlantic THC will undergo changes that will result in substantial and rapid climate change for western Europe and Scandinavia, the probability of this occurring cannot be reliably quantified at present. To assess this probability, it is necessary also to understand other potential drivers of rapid change and the intrinsic variability of the climate system. Progress has been made in acquiring high-quality palaeo observations documenting past rapid climate change (Dansgaard et al. 1989; Alley et al. 1993; Koç Karpuz \& Jansen 1992) and Holocene climate variability (Mann et al. 1998; Briffa et al. 2001). The challenge is to bring together the palaeo data and the climate models, in order to validate the models and develop estimates of uncertainty. This would improve our understanding of rapid climate change and of the intrinsic variability of the system, and test the models' abilities across a range of time-scales that exceeds the period of instrumental records. (McAvaney et al. (2001) summarize the current state of climate models and the use of palaeo data for model testing.)

Finally, it is important to note that present-day observations of the Atlantic THC (or, more precisely, of the meridional overturning circulation (MOC) of which the THC is the dominant component) are inadequate for detecting whether it is changing. Recent observations at a few key locations are suggestive of significant changes occurring in the North Atlantic. These include changes in the characteristics of the cold deep overflows (Hansen et al. 2001) and a freshening of the subsurface and surface waters (Dickson et al. 2002; Häkkinen 2002). A weakening of the MOC may already be in progress, unnoticed.

\section{Scientific challenges and the new NERC programme}

In view of the above, the UK Natural Environment Research Council (NERC) has funded the RAPID programme to investigate and understand the causes of rapid climate change, with a main (but not exclusive) focus on the role of the Atlantic Ocean's THC. Using present-day observations, palaeo data and a hierarchy of models, RAPID is intended to improve understanding of the roles of the THC and other processes in rapid climate change, and of the global and regional impacts of such change. Thus, the ability to monitor and predict future rapid climate change, particularly in the North Atlantic region, will be enhanced. The scientific challenges are encapsulated in the programme objectives, defined by the RAPID scientific steering committee, which are

(1) to establish a pre-operational prototype system to continuously observe the strength and structure of the Atlantic MOC;

(2) to support long-term direct observations of water, heat, salt and ice transports at critical locations in the northern North Atlantic, to quantify the atmospheric and other (e.g. river run-off, ice sheet discharge) forcing of these transports, and to perform process studies of ocean mixing at northern high latitudes; 
(3) to construct well-calibrated and time-resolved palaeo data records of past climate change, including error estimates, with a particular emphasis on the quantification of the timing and magnitude of rapid change at annual to centennial time-scales;

(4) to develop and use high-resolution physical models to synthesize observational data;

(5) to apply a hierarchy of modelling approaches to understand the processes that connect changes in ocean convection and its atmospheric forcing to the largescale transports relevant to the modulation of climate;

(6) to understand, using model experimentation and data (palaeo and present day), the atmosphere's response to large changes in Atlantic northward heat transport, in particular changes in storm tracks, storm frequency, storm strengths, and energy and moisture transports;

(7) to use both instrumental and palaeo data (see 1-3) for the quantitative testing of models' abilities to reproduce climate variability and rapid changes on annual to centennial time-scales and to explore the extent to which these data can provide direct information about the $\mathrm{THC}$ and other possible rapid changes in the climate system and their impact;

(8) to quantify the probability and magnitude of potential future rapid climate change, and the uncertainties in these estimates.

These objectives are clearly interlinked. The ability to predict climate change (8) is predicated on understanding the current state of the climate (particularly a key component like the THC; 1 and 2) and past changes in climate (3), on developing models to investigate the THC and climate (4), on using the models to understand how the system works ( 5 and 6 ) and to test the response of the whole system (7).

RAPID has been funded by the NERC at a level of $£ 20 \mathrm{M}(\mathrm{ca} . \$ 30 \mathrm{M})$ over a period of six years. The first funding decisions were made in November 2002, with studies beginning early in 2003. Table 1 lists the principal investigators (PIs), their institution and the titles of the funded projects. It is not possible here to go into a detailed description of all the projects funded, but they cover a range of palaeo and present-day observations, modelling and statistical methods applied to the problem of rapid climate change. Many of the projects also seek to bridge the 'gaps' between palaeo data, present-day observations and models, and some of the projects are directly complementary (for example, those of Bacon and McCave will both carry out studies at the Eirik Drift, linking present-day and palaeo observations). Taken together with the MOC monitoring projects (see below) the aim is to achieve a comprehensive and integrated view. These projects are the result of the first funding round and RAPID will be issuing further Announcements of Opportunity. These will aim to ensure that the work being carried out addresses all the programme objectives fully and to enhance integration between the different funded projects.

In this short paper, the focus (see $\S 3$ ) will be on observational studies funded to design and implement a prototype Atlantic MOC monitoring system, a key aspect of the RAPID programme (objective 1). These studies compose ca. $25 \%$ of the programme budget and therefore are a major component of RAPID. The eventual aim 
Table 1. List of funded RAPID PIs and project titles

(The science objectives are listed in $\S 2$ of the paper. The first objective (monitoring the MOC) accounts for about one-quarter of the programme budget, and therefore was the subject of a separate Announcement of Opportunity and evaluation process. That evaluation was conducted jointly with the NSF in the USA, and included in the table are the NSF-funded studies that are complementary to the RAPID MOC-observing studies. For more details of the projects see the RAPID Web page, http://rapid.nerc.ac.uk/. SOC, Southampton Oceanography Centre; POL, Proudman Oceanographic Laboratory; UEA, University of East Anglia; UM, University of Miami; URI, University of Rhode Island; WHOI, Woods Hole Oceanographic Institution; UCL, University College London; BAS, British Antarctic Survey.)

\begin{tabular}{ll}
\hline $\begin{array}{c}\text { PI } \\
\text { (institution) }\end{array}$ & \multicolumn{1}{c}{ title } \\
\hline & monitoring the MOC (science objective 1) \\
\hline $\begin{array}{l}\text { Hughes, C. } \\
\text { (POL) }\end{array}$ & A monitoring array along the western margin of the Atlantic. \\
$\begin{array}{l}\text { Marotzke, J. } \\
\text { (SOC) }\end{array}$ & $\begin{array}{l}\text { Monitoring the Atlantic Meridional Overturning Circulation at } \\
26.5^{\circ} \mathrm{N} .\end{array}$ \\
$\begin{array}{l}\text { Watson, A. } \\
\text { Time-series of transient tracers in North Atlantic deep waters. }\end{array}$ \\
\hline
\end{tabular}

complementary NSF-funded studies

Johns, W. An observing system for meridional heat transport variability in (UM) the subtropical North Atlantic.

Rossby, T. The Oleander Project: sustained observation of ocean currents and (URI) transports in the Gulf Stream and adjacent waters from New York to Bermuda.

Toole, J. Investigating the characteristics and consequences of interannual (WHOI) variations in the Northwest Atlantic's deep western boundary current.

science objectives $2-8($ see $\S 2)$

Bacon, S. Cape Farewell and Eirik Ridge: interannual to millennial (SOC) thermohaline circulation variability.

Bamber, J. The role of the cryosphere in modulating the thermohaline (Bristol) circulation of the North Atlantic.

Briffa, K. Quantitative applications of high-resolution Late Holocene proxy (UEA) data sets: estimating climate sensitivity and thermohaline circulation influences.

Bryden, H. Extending the time-series of Atlantic meridional overturning (SOC) backwards in time using historical measurements. 
Table 1. (Cont.)

\begin{tabular}{|c|c|}
\hline $\begin{array}{c}\text { PI } \\
\text { (institution) }\end{array}$ & title \\
\hline $\begin{array}{l}\text { Challenor, P. } \\
\text { (SOC) }\end{array}$ & The probability of rapid climate change. \\
\hline $\begin{array}{l}\text { Fairchild, I. } \\
\text { (Keele) }\end{array}$ & $\begin{array}{l}\text { Atlantic seaboard climate responses including bounding errors } \\
\text { (ASCRIBE). }\end{array}$ \\
\hline $\begin{array}{l}\text { Guilyardi, E. } \\
\text { (Reading) }\end{array}$ & $\begin{array}{l}\text { The role of salinity in ocean circulation and climate response to } \\
\text { greenhouse-gas forcing. }\end{array}$ \\
\hline $\begin{array}{l}\text { Holmes, J. } \\
\text { (UCL) }\end{array}$ & $\begin{array}{l}\text { ISOMAP UK: a combined data-modelling investigation of water } \\
\text { isotopes and their interpretation during rapid climate change } \\
\text { events. }\end{array}$ \\
\hline $\begin{array}{l}\text { Hoskins, B. } \\
\text { (Reading) }\end{array}$ & $\begin{array}{l}\text { The atmospheric water vapour budget and its relevance to the } \\
\text { THC. }\end{array}$ \\
\hline $\begin{array}{l}\text { Josey, S. } \\
\text { (SOC) }\end{array}$ & $\begin{array}{l}\text { The role of air-sea forcing in causing rapid changes in the North } \\
\text { Atlantic thermohaline circulation. }\end{array}$ \\
\hline $\begin{array}{l}\text { McCave, I. N. } \\
\text { (Cambridge) }\end{array}$ & $\begin{array}{l}\text { Hydrographic and flow changes at sharp climate transitions in the } \\
\text { North Atlantic MOC, } 0-16 \text { ka BP. }\end{array}$ \\
\hline $\begin{array}{l}\text { Tudhope, A. } \\
\text { (Edinburgh) }\end{array}$ & $\begin{array}{l}\text { Improving our ability to predict rapid changes in the El Niño } \\
\text { Southern Oscillation climatic phenomenon. }\end{array}$ \\
\hline $\begin{array}{l}\text { Watson, A. } \\
\text { (UEA) }\end{array}$ & $\begin{array}{l}\text { Circulation, overflow, and deep convection studies in the Nordic } \\
\text { seas using tracers and models. }\end{array}$ \\
\hline $\begin{array}{l}\text { Wells, N. } \\
\text { (SOC) }\end{array}$ & $\begin{array}{l}\text { The determination of heat transfer and storage, and their changes } \\
\text { in the North Atlantic Ocean. }\end{array}$ \\
\hline $\begin{array}{l}\text { Williams, R. } \\
\text { (Liverpool) }\end{array}$ & $\begin{array}{l}\text { The role of sloping topography in the overturning circulation of } \\
\text { the North Atlantic. }\end{array}$ \\
\hline $\begin{array}{l}\text { Willmott, A. } \\
\text { (Keele) }\end{array}$ & $\begin{array}{l}\text { Processes controlling dense water formation and transport on } \\
\text { Arctic continental shelves. }\end{array}$ \\
\hline $\begin{array}{l}\text { Wolff, E. } \\
\text { (BAS) }\end{array}$ & $\begin{array}{l}\text { High resolution anatomy of rapid climate transitions in the Last } \\
\text { Glacial period from a Greenland ice core. }\end{array}$ \\
\hline
\end{tabular}

of these studies is to develop a cost-effective means of operationally monitoring the Atlantic MOC that would provide an 'early warning system' for future changes. Given the scale of the problem, RAPID is actively involved in promoting international collaboration. A key collaboration, arising from discussions between the prime ministers of the UK and Norway, is with the Norwegian Ocean Climate project (NOClim, see http://www.noclim.org). With regard to monitoring the Atlantic MOC, collaboration has been established with the National Science Foundation (NSF) in the USA. 
On a broader front, RAPID will contribute to and work with both ASOF (Arctic Subarctic Ocean Fluxes, see http://asof.polar.no and http://psc.apl.washington.edu/ search/ASOF.html) and CLIVAR (http://www.clivar.org).

\section{Observing changes in the Atlantic MOC}

For this part of RAPID, close collaboration has been established between the NERC and NSF, including a joint review of proposals. NSF is funding observations in the North Atlantic that will help to address the first RAPID science objective on monitoring the MOC (see table 1 for a list of the NSF-funded projects that are complementary to the RAPID ones; note that the studies of Johns and Marotzke and of Toole and Hughes are linked). Here the three NERC-funded components of the MOC-observing system are briefly described. The key points to note are that these studies will address the issues of whether the MOC is changing and how changes at high latitudes in the MOC propagate south in the Atlantic. In particular, the $26.5^{\circ} \mathrm{N}$ line and the boundary array will help in determining whether advective or boundary wave effects or some combination of the two accomplish the transfer of the climate signal, while the transient tracers can help to unravel the effects of horizontal recirculations on that signal.

\section{(a) Observing the $M O C$ at $26.5^{\circ} \mathrm{N}$}

The rationale for this project is that it is ultimately the ocean heat transport around $25^{\circ}-35^{\circ} \mathrm{N}$ that is most relevant for climate. Much of the heat transported northwards in the Atlantic is given off to the atmosphere over the Gulf Stream extension (e.g. Isemer et al. 1989), from where it is transported northeastward toward Europe by the atmosphere. Two characteristics of ocean heat-transport mechanisms are crucial. First, the ocean heat transport is mainly accomplished by the MOC (Hall \& Bryden 1982; Ganachaud \& Wunsch 2000). Second, fluctuations in heat transport are expected to be dominated by fluctuations in the transporting velocity field, and only to a lesser extent by variability in heat content (Jayne \& Marotzke 2001). Thus monitoring the MOC will give insight also into the heat transport changes. Monitoring at $26.5^{\circ} \mathrm{N}$ has the triple advantage of being close to the heat transport maximum in the Atlantic, of being the latitude of four modern hydrographic occupations, and of offering a long time-series of boundary current observations not available anywhere else (Baringer \& Larsen 2001; work being continued under the NSF-funded study by Johns). Since it is not practical to monitor the MOC by constantly manning a hydrographic section across the ocean basin, an alternative approach is required.

The approach relies on a combination of moored arrays (temperature, salinity, currents and pressure), hydrographic lines, satellite observations (sea level, winds), the opportunistic use of float data, underwater-cable measurements (Florida Straits transport) and modelling to synthesize the observations. The starting point lies in applying geostrophy: geostrophic mass transport between any two points depends only on the pressure difference between these points; to estimate the MOC thus requires the continuous observation of density at the eastern and western boundaries, plus the establishment of a reference level. This idea has been implemented previously in various ways, though not in a systematic attempt to observe the MOC continuously (Whitworth 1983; Lynch-Stieglitz et al. 1999; McPhaden \& Zhang 2002; 

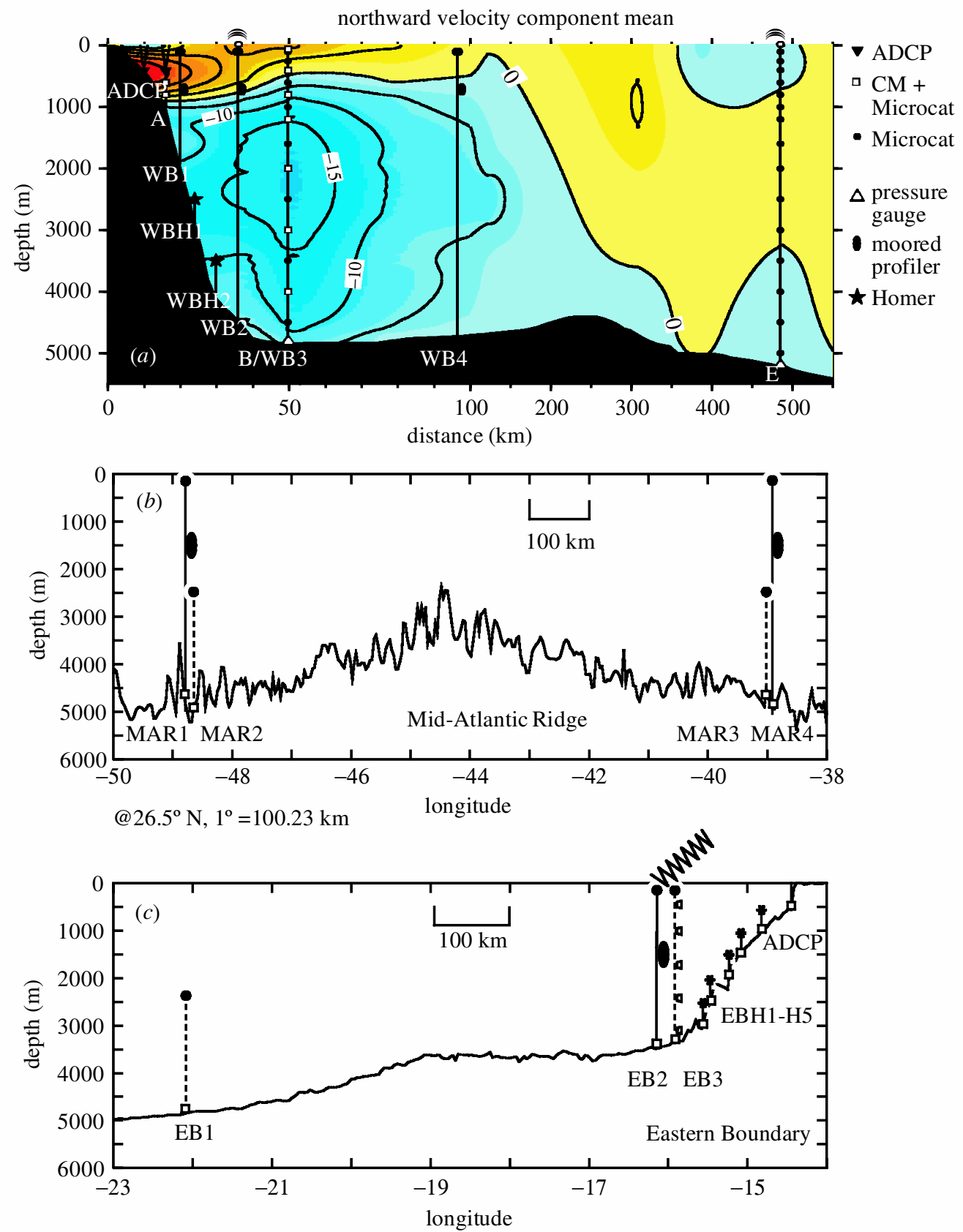

Figure 1. Schematic of the monitoring system at $26.5^{\circ} \mathrm{N}$, showing deployment of moorings at (a) the western boundary (the background is long-term averaged meridional velocity (Lee et al. 1996)), (b) the Mid-Atlantic Ridge and (c) the eastern boundary.

Marotzke et al. 1999). The $26.5^{\circ} \mathrm{N}$ section has the fundamental advantage that the western boundary current (flow through the Florida Straits) can be measured relatively straightforwardly by underwater cable (Baringer \& Larsen 2001) and regular 

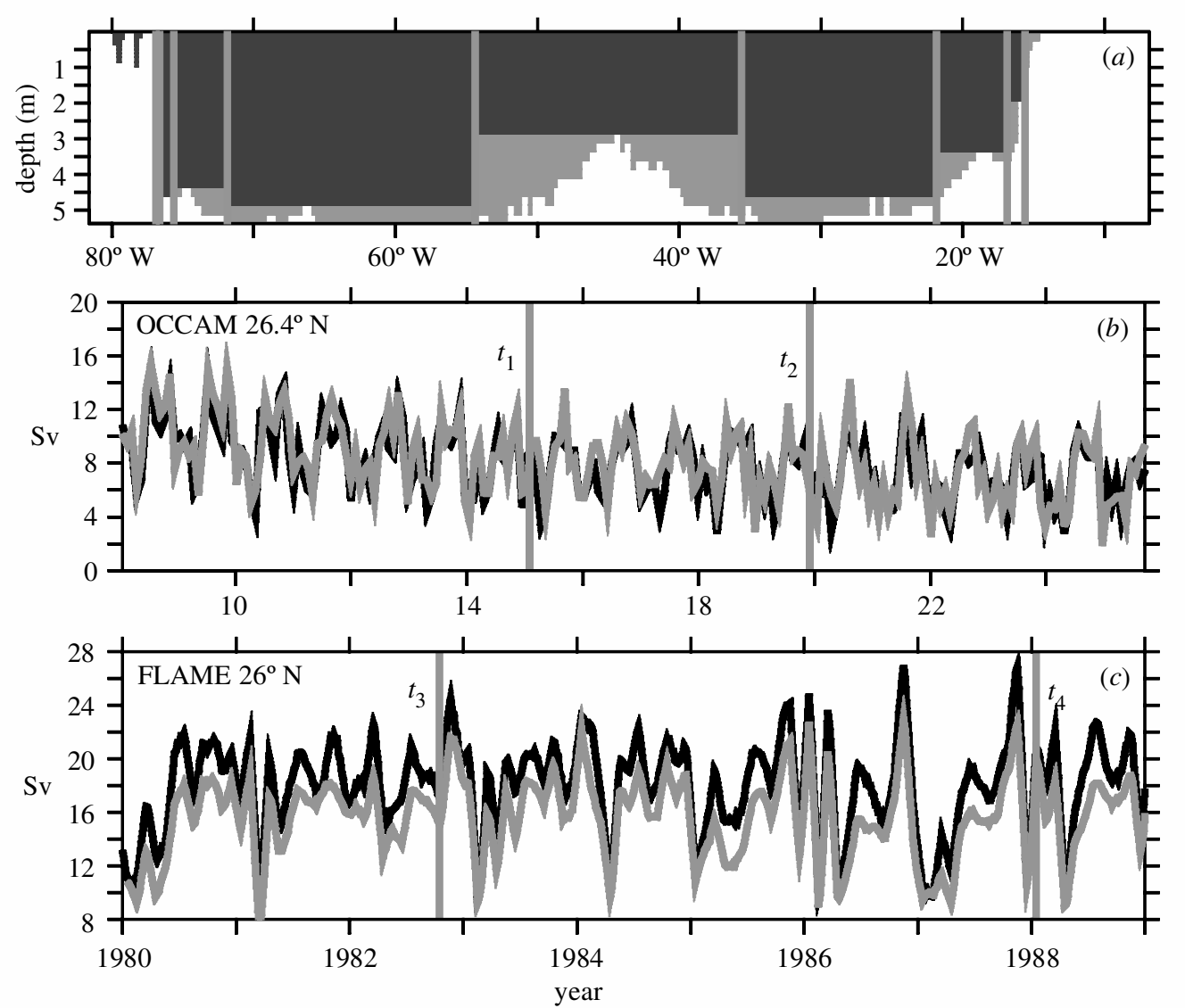

Figure 2. Reconstruction of the MOC of two high-resolution numerical models, based on the proposed mooring design. (a) Location of the moorings. Dark shading marks areas across which thermal wind shear is captured by the array; light shading marks 'leakage' area. (b) Time-series, maximum MOC (black) and maximum reconstruction (grey) for OCCAM. (c) Time-series, maximum MOC (black) and maximum reconstruction (grey) for FLAME. For an updated version of these results see Hirschi et al. (2003).

calibration cruises. This makes the monitoring of the entire MOC equivalent to the task of monitoring the depth profile at which the flow through the Florida Straits returns southwards. Currently, its contribution to the MOC returns southwards at depths between 1000 and 4000 m (e.g. Roemmich \& Wunsch 1985); dramatic shoaling of this return path would be equivalent to a collapse of the MOC (there is always expected to be wind-driven flow through the Florida Straits).

To monitor continuously full-depth density profiles at and near the eastern and western boundaries, eight full-depth moorings will be deployed (figure 1). Six of these will be equipped with a McLane Moored Profiler, taking roughly one CTD (conductivity, temperature, depth) profile every other day. The other two moorings will be conventional full-depth moorings with fixed-depth CTDs. All moorings would also be equipped with bottom pressure sensors, and some with current meters. These give added information for estimating the depth-independent part of the MOC that is not in thermal wind balance but dominated by high-frequency barotropic dynamics 

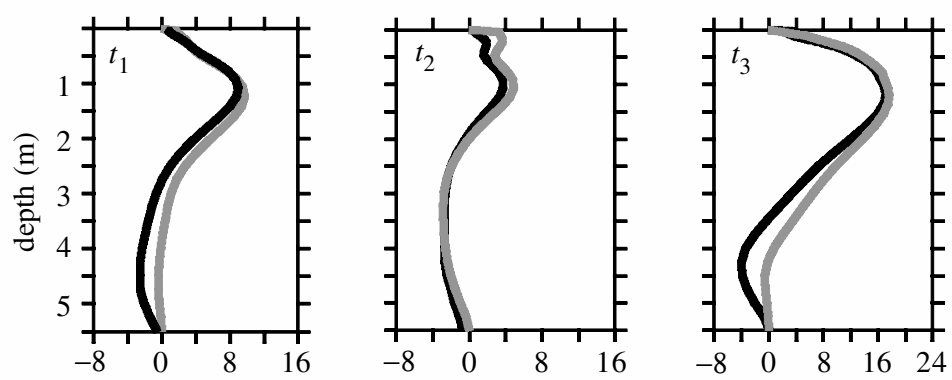

(d)
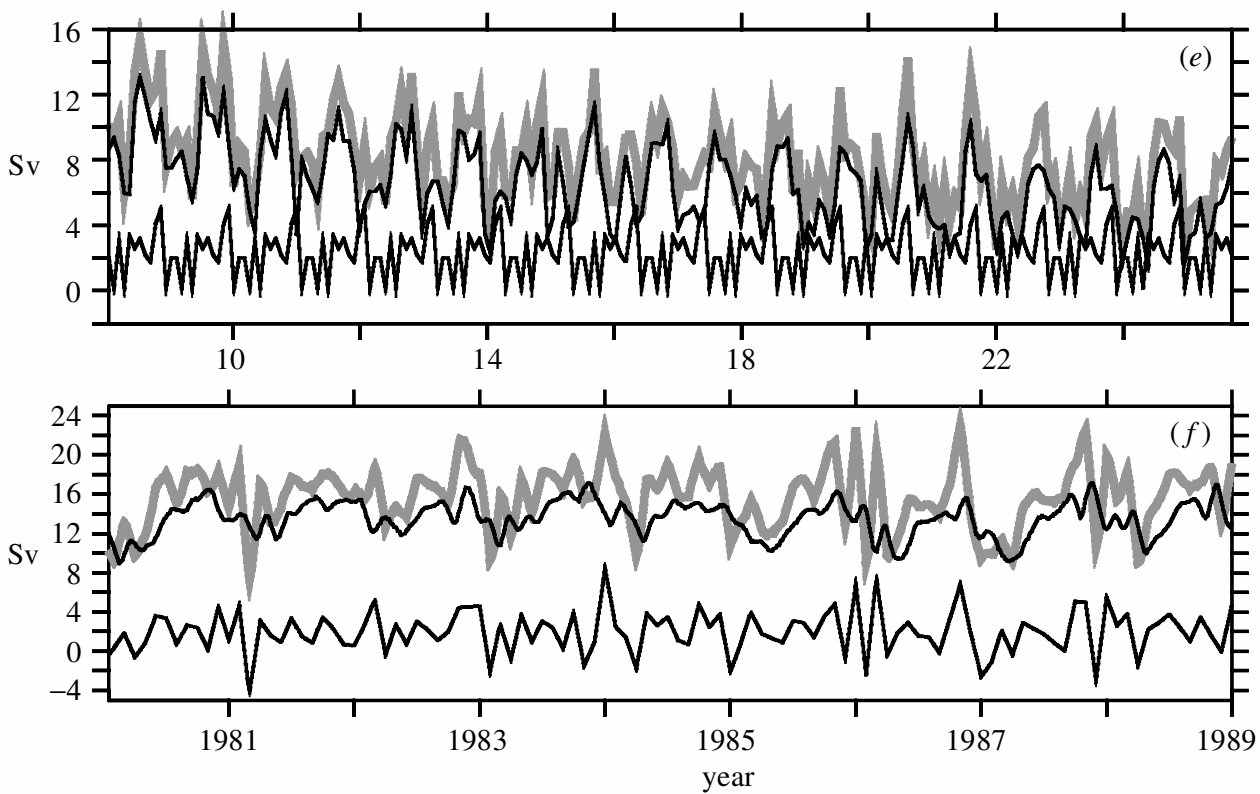

Figure 2. (Cont.) (d) Vertical profiles of MOC (black) and reconstruction (grey), at times indicated in $(b)$ and $(c)$. (e) Decomposition of reconstruction (grey) into contributions from thermal wind (upper thin line) and Ekman transport (lower thin line), for OCCAM. $(f)$ Decomposition of reconstruction (grey) into contributions from thermal wind (upper thin line) and Ekman transport (lower thin line), for FLAME. For an updated version of these results see Hirschi $e t$ al. (2003).

(Jayne \& Marotzke 2001). To test the array, two transoceanic-ship-based sections will be carried out to obtain hydrographic MOC estimates, towards the beginning and the end of the deployment period. The presence of the Mid-Atlantic Ridge (MAR) complicates the endpoint monitoring, because a pressure drop may exist across the ridge. Below the ridge crest, the sub-basins to the east and west therefore have to be monitored separately (figure 1). In addition, the sloping shelf-break topography, from the deep water to shallow depths, will be instrumented with CTDs, bottom pressure recorders (BPRs), and current meters, to obtain continuous observations at fixed depths. This provides an alternative vertical sampling strategy, and also helps to solve the so-called bottom-triangle problem (Whitworth \& Peterson 1985).

This monitoring system has been tested by being 'deployed' in two high-resolution ('eddy-permitting') numerical models, OCCAM (Webb 1996; $\frac{1}{4}^{\circ}$ resolution) and 
FLAME (Dengg et al. $1999 ; \frac{1}{3}^{\circ}$ resolution). The MOC is reconstructed based on a superposition of Ekman and thermal wind contributions (cf. Lee \& Marotzke 1998). Knowing the wind stress allows the determination of the Ekman transport from theory. It is assumed that the Ekman transport is compensated for by a spatially constant return flow across the section, so that there is no net meridional mass transport related to the zonal wind stress. The thermal wind balance allows the calculation of the vertical shear of the meridional velocity component between adjacent vertical density profiles, across the section. Integrating the shear from bottom to top yields a meridional velocity field. As for the Ekman transport, a spatially (but not temporally) constant correction is applied to the velocity field in order to ensure zero net meridional mass transport. The vertical profile of mass transport across the Florida Strait is assumed to be known (according to the information the underwater cable measurements and profiling sections could provide in the real Atlantic). Figure $2 b, c$ demonstrates that the reconstruction does an good job in recovering the time history of the maximum MOC, at $26^{\circ} \mathrm{N}$. The FLAME analysis shows a slight bias of ca. $2 \mathrm{~Sv}$, but the variability is very well reproduced. Figure $2 d$ shows that the reconstruction reproduces the vertical structure of the MOC, as well as the evolution of the maximum. Figure $2 e, f$ shows that it is both contributions to the reconstruction (thermal wind and Ekman) that are required to capture the total MOC. Other numerical tests of the system design (results not shown) suggest that it should be possible to monitor the MOC using this approach.

\section{(b) A monitoring array along the western margin of the Atlantic}

Here the aim is to monitor the propagation of signals along the western boundary of the North Atlantic. Boundary waves represent the rapid, integrated response of the mid- and low-latitude ocean to deep-water formation events at high latitudes, and should allow changes in MOC at mid latitudes (as seen by the $26.5^{\circ} \mathrm{N}$ array, see above) to be attributed to their high-latitude sources. The overturning circulation can respond far more rapidly and directly to high-latitude forcing through boundary Kelvin waves, or more generally coastal-trapped waves (Huthnance 1978) compared to the advective effects (Pickart 1992; Dickson \& Brown 1994). The boundary waves remove unsupported boundary pressure anomalies, and rapidly and efficiently communicate MOC anomalies from high to low latitudes. This effect has been seen in a wide hierarchy of models, including highly idealized reduced-gravity models (Kawase 1987; Johnson \& Marshall 2002a,b), idealized ocean global-change models (GCMs) (Yang 1999), global ocean GCMs (Goodman 2001) and the coupled ocean-atmosphere model HadCM3 (Dong \& Sutton 2002).

To monitor such changes, three clusters of combined BPRs and inverted echo sounders, measuring pressure and column-integrated sound speed, and profiling CTDs (HOMing Environmental Recorder or HOMER) will be deployed along the western margin of the North Atlantic, to detect MOC anomalies as they propagate equatorwards (figure 3). The instruments will be deployed along JASON altimeter tracks crossing the slope at about $43^{\circ} \mathrm{N}, 52^{\circ} \mathrm{W}$ (pass 191, downstream of the Grand Banks), $42^{\circ} \mathrm{N}, 60^{\circ} \mathrm{W}$ (pass 176 , near Halifax), and $38^{\circ} \mathrm{N}, 69^{\circ} \mathrm{W}$ (pass 126 , coincident with the WHOI section, NSF-funded Toole study; figure 3 ). The instruments will be placed at depths of $2-4.5 \mathrm{~km}$ in order to resolve the deep western boundary current (DWBC), and should detect the first signatures of changes in 


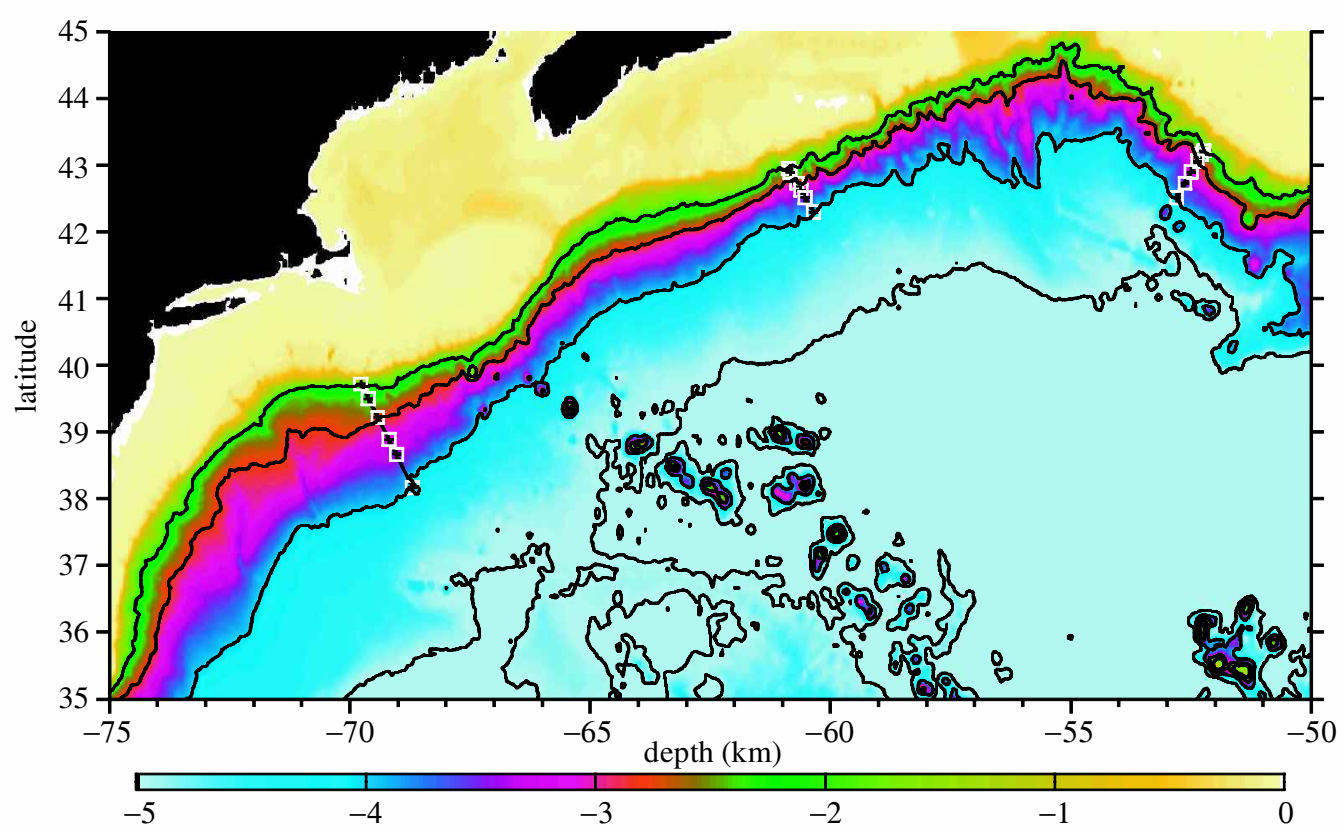

Figure 3. Ocean depth shown by the contours $(2,2.8,4$ and $5 \mathrm{~km})$ with proposed DWBC monitoring lines (with location of the moorings marked by + ).

overturning being communicated from high to low latitudes. A simple calculation based on geostrophic transport integrals, together with the precision of the isopycnal height measurements, suggests that this system will be sufficiently accurate to measure DWBC transport to an accuracy of $1 \mathrm{~Sv}$. This relies on assumptions about the impact of eddies, recirculations, and aliasing of high-frequency signals, which will only be properly assessed by detailed model studies and, a posteriori, from the field measurements. A preliminary assessment of the observational strategy has been made by examining the dynamical response along the western boundary to a perturbation in buoyancy forcing at high latitudes using an isopycnic model (Bleck \& Smith 1990). This experiment demonstrates that high-latitude forcing excites a downstream response at lower latitudes along the western boundary involving three phases: first, rapid (time-scale of months) communication involving changes in the pressure field induced by topographic waves; second, an intermediate time-scale response involving advective changes in layer thickness generated by local circulation anomalies; third, a slower basin-scale advective response (seen in the model by studying the arrival of transient-tracer signals, see figure 4). Overall, the results show that the array should be able to detect such changes.

\section{(c) Time-series of transient tracers in North Atlantic deep waters}

The final component of the monitoring of the MOC is by way of a pilot project looking at the possibility of using transient tracers $\left(\mathrm{SF}_{6},{ }^{129} \mathrm{I}\right)$ to monitor the spreading of waters from northern to mid latitudes. Two Aqualab autosamplers will be deployed on moorings in the North Atlantic to test whether it is possible to obtain adequate in situ tracer measurements. These samplers can collect 50 water samples over a period 

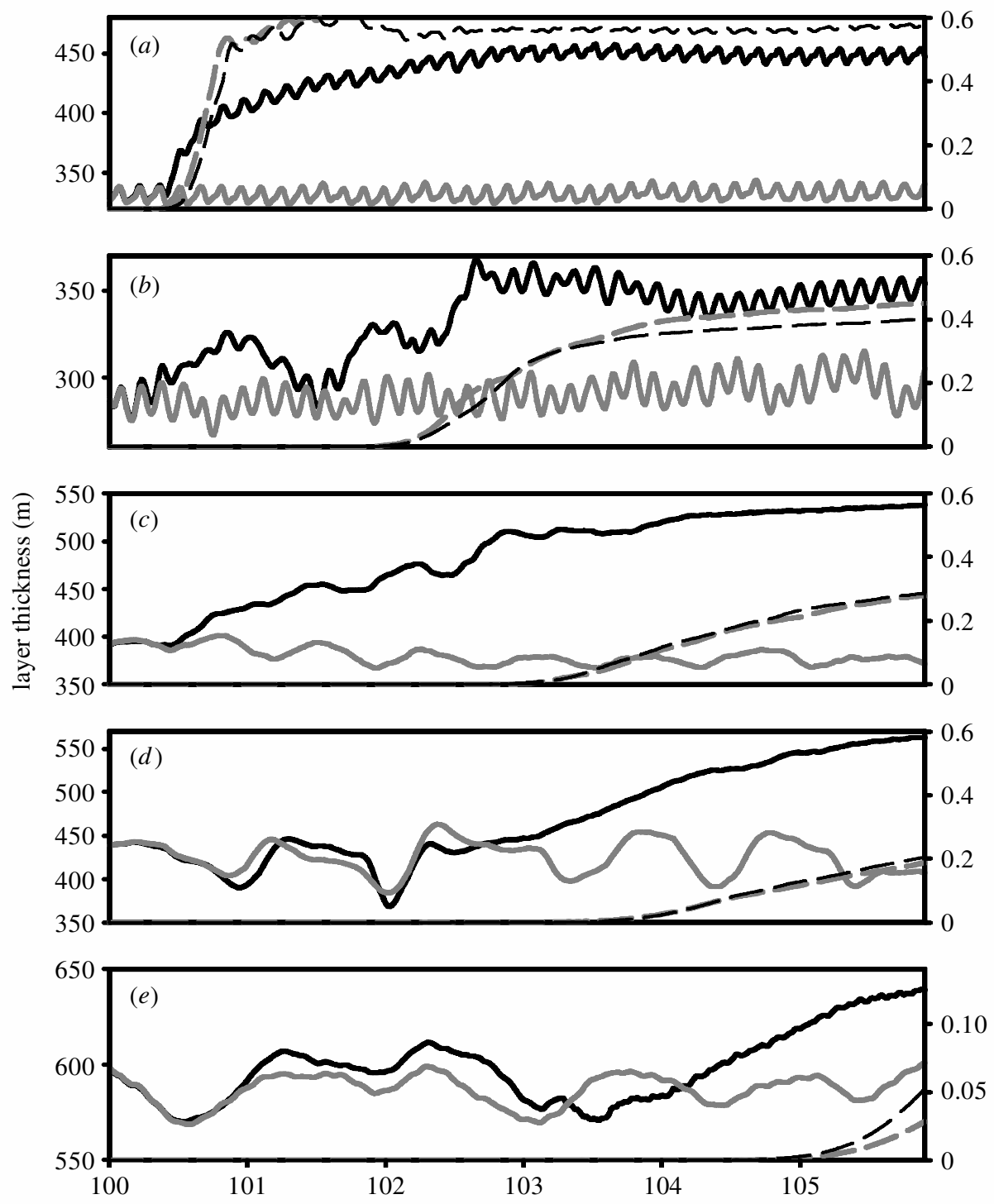

Figure 4. Time-series of model layer thickness and tracer concentration (full and dashed lines, respectively) along the North Atlantic western boundary slope for a dense layer $(\sigma=27.8)$ in model years 100-106 for perturbed (black line) and unperturbed (grey line) integration. The layer is at depths between 3 and $4 \mathrm{~km}$. In the perturbed case, the additional buoyancy forcing at northern latitudes leads to a layer thickness increase over the northern source region. This signal spreads southwards through a combination of a wave and advective response. The layer thickness increases downstream: initially there is sometimes an oscillatory response (e.g. $38^{\circ} \mathrm{N}$ and $26^{\circ} \mathrm{N}$ ) and a more systematic increase in thickness when the transient-tracer front eventually arrives (dashed lines). (a) $50^{\circ} \mathrm{W}, 54^{\circ} \mathrm{N}$; (b) $53^{\circ} \mathrm{W}, 43^{\circ} \mathrm{N} ;$ (c) $60^{\circ} \mathrm{W}, 42^{\circ} \mathrm{N}$; (d) $68.8^{\circ} \mathrm{W}, 37.7^{\circ} \mathrm{N}$; (e) $76^{\circ} \mathrm{W}, 26^{\circ} \mathrm{N}$. 
of a year, using the novel technology of titanium foil bags for the samples. If the pilot deployment proves successful, then further autosamplers may be deployed on moorings around the boundary of the North Atlantic. This will determine whether the tracers that have been detected $\left({ }^{129} \mathrm{I}\right.$; Edmonds et al. 2001$)$ or released $\left(\mathrm{SF}_{6}\right.$; Watson et al. 1999) at higher latitudes can be followed to lower latitudes, in particular as they are advected along the western boundary. This approach will complement the hydrographic and dynamical measurements described above and will allow the determination of recirculation pathways. It will also take advantage of the fact that the source functions for the tracers are changing rapidly (for example, ${ }^{129} \mathrm{I}$ is a product of nuclear-fuel reprocessing from northwest Europe, and its source rose rapidly through the first part of the 1990s, and has remained roughly constant since), thus allowing clear detection of signals.

\section{(d) Developing novel instruments}

In addition to funding scientific projects, RAPID, through the Small Business Research Initiative, is also funding the development of novel instrumentation. This is to ensure that the instrumentation will be available in a timely manner. Two examples are HOMER - a bottom-mounted CTD-profiling system - and turbulence probes for use on autonomous profiling floats. HOMER is required for both the $26.5^{\circ} \mathrm{N}$ line and the boundary array monitoring systems.

\section{Speculating about future changes}

One of the aims of the RAPID programme is to bring together different insights that might aid our understanding of rapid (abrupt) climate change. Therefore, is seems appropriate to end by speculating on one of many possible mechanisms that arise out of a number of recent insights into the ocean and climate system. The chosen example highlights some of the challenges that face any attempt to derive a coherent picture of rapid changes.

The Agulhas current system feeds water from the Indian Ocean into the South Atlantic through the mechanism of oceanic eddies (rings) shed from the Agulhas Retroflection (south of Africa; see figure 1 of Quartly \& Srokosz (2002) for a schematic). These rings move into the South Atlantic, transporting heat and salt, contributing to the so-called global 'conveyor belt' ocean circulation. At present, coupled climate models do not completely resolve the rings, so their influence on the MOC is not captured fully (see Treguier et al. 2003). A simpler modelling study (Weijer et al. 2002) has shown that if this so-called 'Agulhas leakage' is stopped (which it probably was in times past), then the MOC becomes more susceptible to disruption by changes in freshwater input in the northern North Atlantic. The shedding of Agulhas rings is related to the flow around Madagascar: that flow being one of the sources of the Agulhas Current (Schouten et al. 2002a,b; Quartly \& Srokosz 2002). It has been observed from radar altimeter satellite data (Schouten et al. 2002b) that the flow round Madagascar was disrupted in 1999 and that that, in turn, affected the Agulhas-ring shedding from early 2000. The Retroflection itself was more easterly during the period October 2000 to March 2001, with an apparent lack of ring shedding (Quartly \& Srokosz 2002; see also figure 5). This disruption seems to be linked to the propagation of signals to Madagascar across the Indian Ocean associated with the 1997-1998 El Niño (Schouten et al. 2002b; also figure 6). 


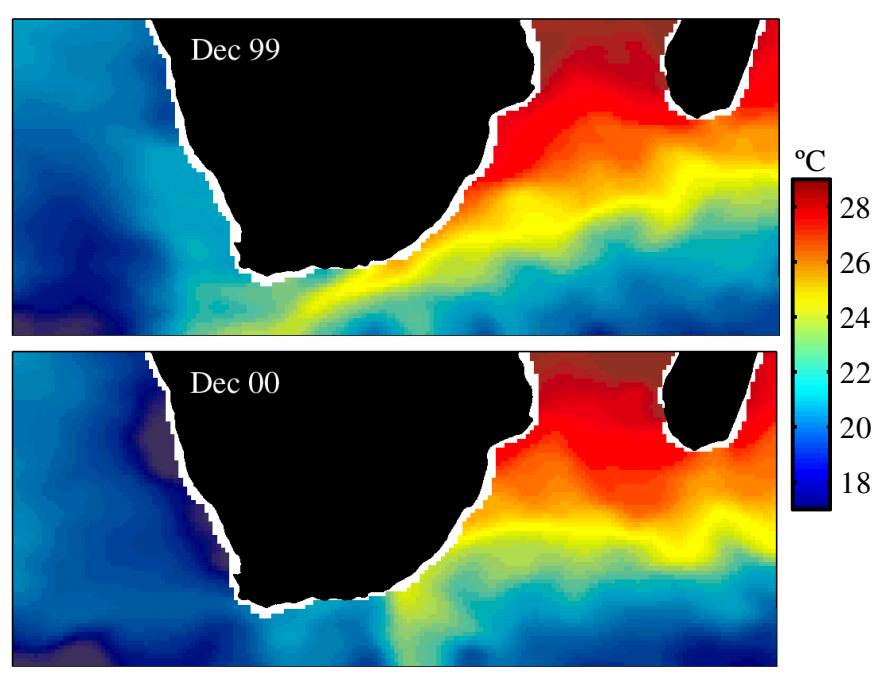

Figure 5. Passive microwave sea-surface temperature (SST) data, from the TRMM (Tropical Rainfall Monitoring Mission) Microwave Imager (TMI), showing the early (more easterly) retroflection of the Agulhas in December 2000, as compared to December 1999 (the more usual situation). This situation lasted from October 2000 to March 2001. Note that TRMM is in a low-inclination orbit, so data are only available to $38^{\circ} \mathrm{S}$.

The above is known, so now consider some more speculative aspects. Global warming could lead to changes in El Niño: both in its frequency and amplitude (Cubasch et al. 2001); note that one of the RAPID projects is looking at changes in El Niño (Tudhope, table 1). These in turn might lead to a significant disruption of the Agulhas leakage and so make the Atlantic MOC more susceptible to rapid change associated with changes in northern North Atlantic freshwater fluxes. This scenario takes no account of any potential feedbacks in the system. However, it does point up a number of issues where our ability to study potential rapid climate change is lacking. First, current climate models do not capture the full effects of the oceanic mesoscale (rings, eddies, fronts), but the next generation may do so better. Second, the 1990s were a decade of unprecedented satellite observations of the ocean on a global scale. These have enabled the study of transoceanic signals that might affect the global circulation. However, a decade (or even two decades) of such observations is hardly adequate to unravel all the possible climate linkages in the ocean. Third, in situ observations of aspects of the Agulhas system (e.g. the flow round Madagascar) are sparse, as is also the case for many other parts of the global ocean circulation. This latter point is being addressed to some extent by the ARGO float programme (Roemmich \& Owens 2000), data from which will be used in RAPID.

It is clear that the RAPID programme in isolation cannot address all aspects of rapid/abrupt climate change. Instead it aims to make progress on a number of fronts (as described above; $\S \S 2$ and 3 ). In terms of observations, a key component of RAPID is the MOC-observing system, which will provide a unique insight into the circulation of the North Atlantic, in conjunction with other international observing efforts. By combining the observations with modelling and palaeo studies a better understanding of the potential for, and the ability to predict, rapid climate change should emerge from the programme. 


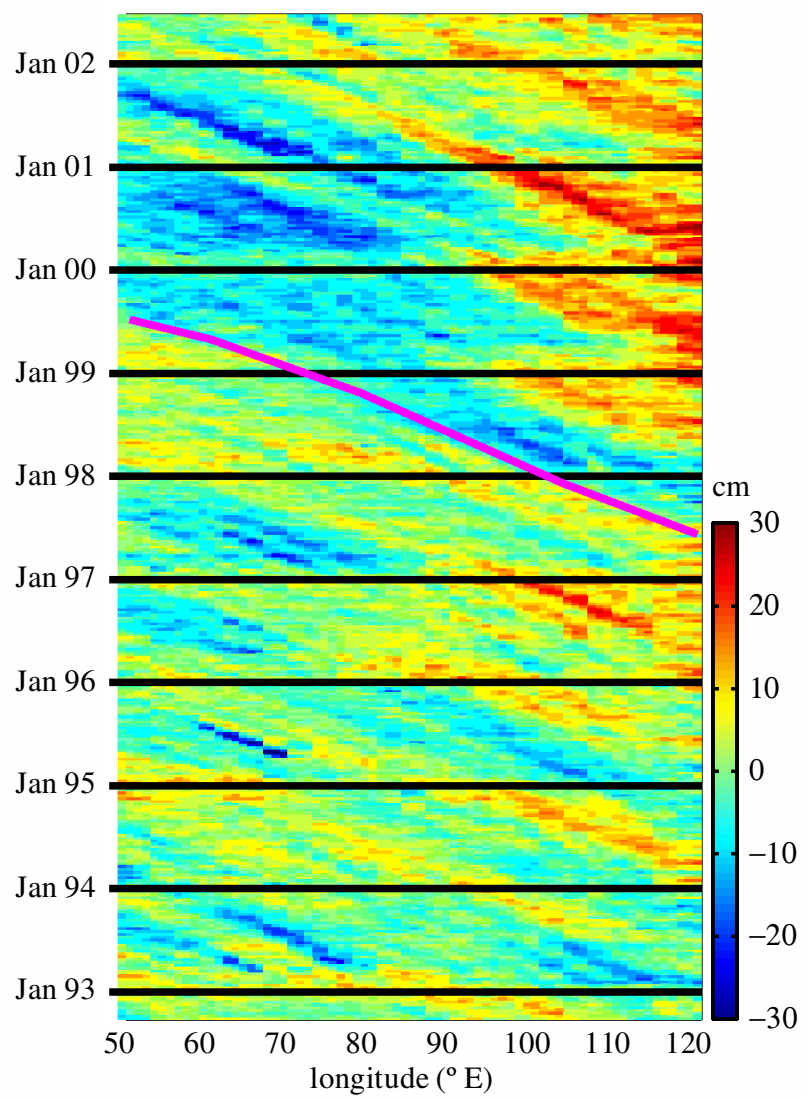

Figure 6. Hovmöller diagram of TOPEX sea-surface height anomalies at the approximate latitude of the South Equatorial Current (SEC; $16-19^{\circ} \mathrm{S}$ ) from $50^{\circ}$ to $120^{\circ} \mathrm{E}$ in the Indian Ocean. The superimposed pink line shows the propagation of a signal from the eastern Indian Ocean, associated with the 1997-1998 El Niño, to the coast of Madagascar. This suggests that the El Niño disrupted the SEC and the signal (pink line) reached the coast of Madagascar in mid 1999.

For more information see the RAPID Web page http://rapid.nerc.ac.uk/.

This paper could not have been written without the RAPID team (Dr P. Newton, Dr C. Gommenginger and Dr C. Yeomans), the RAPID Steering Committee and the RAPID PIs. I am particularly grateful to Professor J. Marotzke and Dr C. Hughes for help with the material on the MOC monitoring systems, and to my colleague Dr G. Quartly for the figures of the Agulhas system.

\section{References}

Alley, R. B. (and 10 others) 1993 Abrupt increase in Greenland snow accumulation at the end of the Younger Dryas event. Nature 362, 527-529.

Baringer, M. O. \& Larsen, J. C. 2001 Sixteen years of Florida Current transport at $27^{\circ}$ N. Geophys. Res. Lett. 28, 3179-3182.

Bleck, R. \& Smith, L. T. 1990 A wind-driven isopycnic coordinate model of the North and equatorial Atlantic Ocean. I. Model development and supporting experiments. J. Geophys. Res. 95, 3273-3285. 
Briffa, K. R., Osborn, T. J., Schweingruber, F. H., Harris, I. C., Jones, P. D., Shiyatov, S. G. \& Vaganov, E. A. 2001 Low-frequency temperature variations from a northern tree ring density network. J. Geophys. Res. 106, 2929-2941.

Broecker, W. S. 2000 Abrupt climate change: causal constraints provided by the paleoclimate record. Earth Sci. Rev. 51, 137-154.

Broecker, W. S. \& Denton, G. H. 1989 The role of ocean-atmosphere reorganisations in glacial cycles. Geochim. Cosmochim. Acta 53, 2465-2501.

Cubasch, U., Meehl, G. A., Boer, G. J., Stouffer, R. J., Dix, M., Noda, A., Senior, C. A., Raper, S. \& Yap, K. S. 2001 Projections of future climate change. In Climate change 2001: the scientific basis. Contribution of Working Group I to the Third Assessment Report of the International Panel on Climate Change. (ed. J. T. Houghton, Y. Ding, D. J. Griggs, M. Noguer, P. J. van der Linden, X. Dai, K. Maskell \& C. A. Johnson). Cambridge University Press.

Dansgaard, W., White, J. W. C. \& Johnsen, S. J. 1989 The abrupt termination of the Younger Dryas climate event. Nature 339, 532-534.

Dansgaard, W. (and 10 others) 1993 Evidence for general instability of past climate from a 250 kyr ice-core record. Nature 364, 218-220.

Dengg, J., Bönvig, C. W., Ernst, U., Redler, R. \& Beckmann, A. 1999 Effects of an improved model representation of overflow water on the subpolar North Atlantic. Int. WOCE Newsl. 37, 10-15.

Dickson, R. R. \& Brown, J. 1994 The production of North Atlantic Deep Water: sources, rates and pathways. J. Geophys. Res. 99, 12 319-12341.

Dickson, B., Yashayaev, I., Meincke, J., Turrell, B., Dye, S. \& Holfort, J. 2002 Rapid freshening of the deep North Atlantic Ocean over the past four decades. Nature 416, 832-837.

Dong, B.-W. \& Sutton, R. T. 2002 Adjustment of the coupled ocean-atmosphere system to a sudden change in the thermohaline circulation. Geophys. Res. Lett. 29. (DOI: 10.1029/2002GL015229.)

Edmonds, H. N., Zhou, Z. Q., Raisbeck, G. M., Yiou, F., Kilius, L. \& Edmond, J. M. 2001 Distribution and behaviour of anthropogenic ${ }^{129} \mathrm{I}$ in water masses ventilating the North Atlantic Ocean. J. Geophys. Res. 106, 6881-6894.

Ganachaud, A. \& Wunsch, C. 2000 Improved estimates of global ocean circulation, heat transport and mixing from hydrographic data. Nature 408, 453-457. (Correction (2001) Nature 410, 240.)

Gent, P. R. 2001 Will the North Atlantic Ocean thermohaline circulation weaken during the 21st century? Geophys. Res. Lett. 28, 1023-1026.

Goodman, P. J. 2001 Thermocline adjustment and advection in an OGCM. J. Phys. Oceanogr. 31, 1477-1497.

Häkkinen, S. 2002 Freshening of the Labrador Sea surface waters in the 1990s: another great salinity anomaly? Geophys. Res. Lett. 29, 2232. (DOI: 10.1029/2002/GL015243.)

Hall, M. M. \& Bryden, H. L. 1982 Direct estimates and mechanisms of ocean heat transport. Deep Sea Res. 29, 339-359.

Hansen, B., Turrell, W. R. \& Østerhus, S. 2001 Decreasing overflow from the Nordic seas into the Atlantic Ocean through the Faroe Bank Channel since 1950. Nature 411, 927-930.

Hirschi, J., Baehr, J., Marotzke, J., Stark, J., Cunningham, S. \& Beismann, J.-O. 2003 A monitoring design for the Atlantic meridional overturning circulation. Geophys. Res. Lett. 30. (DOI: 10.1029/2002GL016776.)

Huthnance, J. M. 1978 On coastal-trapped waves: analysis and numerical calculation by inverse iteration. J. Phys. Oceanogr. 8, 74-92.

Isemer, H.-J., Willebrand, J. \& Hasse, L. 1989 Fine adjustment of large scale air-sea energy flux parameterizations by direct estimates of ocean heat transport. J. Climate 2, 1173-1184. 
Jayne, S. R. \& Marotzke, J. 2001 The dynamics of ocean heat transport variability. Rev. Geophys. 39, 385-411.

Johnson, H. L. \& Marshall, D. P. $2002 a$ A theory for the surface Atlantic response to thermohaline variability. J. Phys. Oceanogr. 32, 1121-1132.

Johnson, H. L. \& Marshall, D. P. $2002 b$ Localization of abrupt change in the North Atlantic thermohaline circulation. Geophys. Res. Lett. 29. (DOI: 10.1029/2001GL014140.)

Kawase, M. 1987 Establishment of deep ocean circulation driven by deep water production. $J$. Phys. Oceanogr. 17, 2294-2317.

Koç Karpuz, N. \& Jansen, E. 1992 A high resolution diatom record of the last deglaciation from the SE Norwegian Sea: documentation of rapid climatic changes. Paleoceanography $\mathbf{7}$, 499-520.

Latif, M., Roeckner, E., Mikolajewicz, U. \& Voss, R. 2000 Tropical stabilisation of the thermohaline circulation in a greenhouse warming simulation. J. Clim. 13, 1809-1813.

Lee, T. \& Marotzke, J. 1998 Seasonal cycles of meridional overturning and heat transport of the Indian Ocean. J. Phys. Oceanogr. 28, 923-943.

Lee, T. N., Johns, W., Zantopp, R. \& Fillenbaum, E. 1996 Moored observations of Western Boundary Current variability and thermohaline circulation at $26.5^{\circ} \mathrm{N}$ in the subtropical North Atlantic. J. Phys. Oceanogr. 26, 962-983.

Lynch-Stieglitz, J., Curry, W. B. \& Slowey, N. 1999 Weaker Gulf Stream in the Florida Straits during the Last Glacial Maximum. Nature 402, 644-647.

McAvaney, B. J., Covey, C., Joussaume, S., Kattsov, V., Kitoh, A., Ogana, W., Pitman, A. J., Weaver, A. J., Wood, R. A. \& Zhao, Z.-C. 2001 Model evaluation. In Climate change 2001: the scientific basis. Contribution of Working Group I to the Third Assessment Report of the International Panel on Climate Change. (ed. J. T. Houghton, Y. Ding, D. J. Griggs, M. Noguer, P. J. van der Linden, X. Dai, K. Maskell \& C. A. Johnson). Cambridge University Press.

McPhaden, M. J. \& Zhang, D. 2002 Slowdown of the meridional overturning circulation in the upper Pacific Ocean. Nature 415, 603-608.

Manabe, S. \& Stouffer, R. J. 1988 Two stable equilibria of a coupled ocean-atmosphere model. J. Clim. 1, 841-866.

Manabe, S. \& Stouffer, R. J. 1993 Century scale effects of increased atmospheric $\mathrm{CO}_{2}$ on the ocean-atmosphere system. Nature 364, 215-218.

Mann, M. E., Bradley, R. S. \& Hughes, M. K. 1998 Global-scale temperature patterns and climate forcing over the past six centuries. Nature 392, 779-787.

Marotzke, J., Giering, R., Zhang, Q. K., Stammer, D., Hill, C. N. \& Lee, T. 1999 Construction of the adjoint MIT ocean general circulation model and application to Atlantic heat transport sensitivity. J. Geophys. Res. 104, 29 529-29548.

Pickart, R. S. 1992 Water mass components of the North Atlantic deep western boundary current. Deep Sea Res. 39, 1553-1572.

Quartly, G. D. \& Srokosz, M. A. 2002 TMI observations of the Agulhas and Madagascar retroflections. J. Phys. Oceanogr. 32, 1585-1592.

Roemmich, D. \& Owens, W. B. 2000 The Argo Project: global ocean observations for understanding and prediction of climate variability. Oceanography 13, 45-50.

Roemmich, D. \& Wunsch, C. 1985 Two transatlantic sections: meridional circulation and heat flux in the subtropical North Atlantic Ocean. Deep Sea Res. 32, 619-664.

Schiller, A., Mikolajewicz, U. \& Voss, R. 1997 The stability of the thermohaline circulation in a coupled ocean-atmosphere general circulation model. Climate Dynam. 13, 325-347.

Schouten, M. W., de Ruijter, W. P. M. \& van Leeuwen, P. J. $2002 a$ Upstream control of Agulhas Ring shedding. J. Geophys. Res. 107. (DOI: 10.1029/2001JC000804.) 
Schouten, M. W., de Ruijter, W. P. M., van Leeuwen, P. J. \& Dijkstra, H. A. $2002 b$ An oceanic teleconnection between the equatorial and southern Indian Ocean. Geophys. Res. Lett. 29. (DOI: 10.1029/2001GL014542.)

Treguier, A. M., Boebel, O., Barnier, B. \& Madec, G. 2003 Agulhas eddy flux in a $1 / 6^{\circ}$ Atlantic model. Deep-Sea Res. II 50, 251-280.

Vellinga, M. \& Wood, R. A. 2002 Global climate impacts of a collapse of the Atlantic thermohaline circulation. Climatic Change 54, 251-267.

Watson, A. J. (and 16 others) 1999 Mixing and convection in the Greenland Sea from a tracerrelease experiment. Nature 401, 902-904.

Webb, D. J. 1996 An ocean model code for array processor computers. Comput. Geosci. 22, 569-578.

Weijer, W., de Ruijter, W. P. M. \& Dijkstra, H. A. 2002 The stability of the Atlantic overturning circulation: competition between Bering Strait freshwater flux and Agulhas heat and salt sources. J. Phys. Oceanogr. 31, 2385-2402.

Whitworth, T. 1983 Monitoring the transport of the Antarctic Circumpolar Current at Drake Passage. J. Phys. Oceanogr. 13, 2045-2057.

Whitworth, T. \& Peterson, R. G. 1985 Volume transport of the Antarctic Circumpolar Current from bottom pressure measurements. J. Phys. Oceanogr. 15, 810-816.

Wood, R. A., Keen, A. B., Mitchell, J. F. B. \& Gregory, J. M. 1999 Changing spatial structure of the thermohaline circulation in response to atmospheric $\mathrm{CO}_{2}$ forcing in a climate model. Nature 399, 572-575.

Yang, J. 1999 A linkage between decadal climate variations in the Labrador Sea and the tropical Atlantic Ocean. Geophys. Res. Lett. 26, 1023-1026. 